\title{
O afastamento do humano: isolamento, imobilidade e a relação homem- máquina. Uma leitura de A máquina de Joseph Walser
}

\author{
Renata Quintella de Oliveira ${ }^{1}$
}

\author{
Universidade Federal do Rio de Janeiro
}

\begin{abstract}
Resumo: Em A máquina de Joseph Walser, de Gonçalo M. Tavares, observamos a construção de um personagem que emblematiza o afastamento do homem de sua própria humanidade. Joseph Walser, protagonista deste romance que compõe o segundo momento de uma tetralogia denominada pelo autor como "O Reino", apresenta características como o isolamento, a imobilidade e a alienação. Segundo Hannah Arendt, tais características constituir-se-iam naquelas que originaram o espírito totalitário. A relação homem-máquina também é de fundamental importância neste texto ficcional tavariano, deixando evidente a transformação do trabalho em labor, fazendo com que a máquina/instrumento tome uma dimensão que transcende a meramente instrumental; passa a fazer parte do ciclo vital. $\mathrm{O}$ homem passa a se adequar às condições impostas pela máquina e não o contrário, o que contribui, mais uma vez, para que ocorra a desumanização do homem. Este, agora, apresentase como animal laborans. Em nossa análise recorremos, com frequência, a reflexões teóricas de Hannah Arendt em Origens do totalitarismo; A condição humana e Eichmann em Jerusalém: um relato sobre a banalidade do mal. Além da filósofa, aludimos também a algumas reflexões críticas do próprio Gonçalo M. Tavares, em Atlas do corpo e da imaginação.
\end{abstract}

Palavras-chave: Desumanização. Literatura portuguesa contemporânea. Relação homemmáquina.

\section{Introdução}

Este artigo versa sobre a questão da desumanização no romance A Máquina de Joseph Walser, do escritor português contemporâneo Gonçalo M. Tavares. Nosso foco recaiu sobre o protagonista Joseph Walser, no qual tal questão fica evidente através da análise de sua caracterização, em que prevalecem o isolamento, o mutismo, a imobilidade e a alienação. Tais particularidades foram relacionadas por Hannah Arendt como aquelas que promoveram a ascensão de uma mentalidade que culminaria nos regimes totalitários do século XX.

Outra questão que se relaciona diretamente com a desumanização é a relação homemmáquina. Joseph Walser desenvolve com sua máquina de trabalho uma relação simbiótica e

1 Formada em Português-Literatura pela Faculdade de Letras da UFRJ. Possui experiência em ensino de língua portuguesa, literaturas de língua portuguesa e produção textual, nos níveis Fundamental II e Médio. Especialista em Literatura Portuguesa e Africanas (UFRJ) e em Literaturas de Língua Portuguesa (UNESA), Mestre em Literatura Portuguesa (UFRJ) e Doutoranda em Literatura Portuguesa (UFRJ), com pesquisa de Tese a respeito da tetralogia $O$ reino, de Gonçalo M. Tavares. 
quase afetuosa. A filósofa citada anteriormente também refletiu sobre este tema, quando, em A Condição Humana trata do trabalho e do labor. A relação com a máquina, vivenciada pelo animal laborans, traduz uma inversão de papéis: agora é a máquina quem dita as regras ao homem. Este é forçado a se adaptar às condições impostas por ela. A relação entre Walser e "sua" máquina pode ser pensada a partir desses pressupostos arendtianos, que constituíram a base teórica para a confecção deste artigo.

\section{1. “O Senhor Walser está a ouvir?"}

Joseph Walser constitui um personagem peculiar. Seus focos de interesse recaíam, apenas, sobre os seguintes pontos: a sua estranha coleção; o jogo de dados com os colegas de trabalho e a inusitada relação que tinha com a "sua" máquina. O comportamento do personagem era, predominantemente, de total alheamento: por vezes, várias pessoas (incluindo Klober) lhe perguntavam: "O Senhor Walser está a ouvir?", pois ele parecia estar com a mente em outro lugar. No decorrer da leitura, vemos que Walser realmente tinha o pensamento em outra direção: sua atenção voltava-se, quase que exclusivamente, para as peças metálicas que poderiam ou não fazer parte de sua coleção e na forma que encontraria para obtê-las. Mas o narrador só nos deixa a par deste detalhe mais à frente.

Hanna Arendt trata da questão do isolamento/solidão. Segundo a filósofa, o avanço do movimento nazista foi possível, dentre outros fatores, devido ao encolhimento da esfera pública, que ocorreu devido ao isolamento decorrente das transformações modernas. Em Origens do totalitarismo, Arendt assinala que o isolamento define-se como "aquele impasse no qual os homens se veem quando a esfera política de suas vidas, onde agem em conjunto na realização de um interesse comum, é destruída" (ARENDT, 1989, p. 527). Bordini, que também recorre às reflexões de Hannah Arendt, afirma que, para a filósofa, "[...] diferentemente das simples tiranias, o totalitarismo elimina até o espaço da vida privada, de modo que a lógica totalitária destrói não só a capacidade de agir, mas também a de sentir e pensar" (BORDINI, 2014, p. 149). A pesquisadora referida esclarece que o isolamento e a solidão são condições diferentes. Segundo a crítica:

O domínio totalitário não se baseia apenas no isolamento, que é a destruição da esfera pública, das capacidades políticas dos indivíduos, mas também na solidão, (ou no desenraizamento, como anteriormente mencionei), a qual advém da destruição da vida privada e gera a 'experiência de não se pertencer ao mundo' (BORDINI, 2014, p. 150). 
Em Joseph Walser, como nos confirma Bordini, podemos presenciar tanto o isolamento, "que desponta na sua recusa a se envolver em questões cujo interesse ele poderia compartilhar com os demais (tais como a guerra e a resistência)" (BORDINI, 2010, p. 150), quanto a solidão, "que se mostra principalmente na sua incapacidade de manter laços pessoais e afetivos e está iconizada [...] na coleção de peças metálicas à qual ele se dedica" (BORDINI, 2014, p. 150).

É interessante destacar, ainda, o fato de Bordini ressaltar que tais características do protagonista - o isolamento e a solidão - fazem Klober afirmar que "admira" Walser, justamente por este possuir tais particularidades, na medida em que, desta forma, se encaixaria perfeitamente na descrição que o encarregado faz da figura dos "verdadeiros Homens", presente em sua "teoria”: "os que rejeitam a História e a moral, isto é, rejeitam toda forma de existência coletiva para que a sua existência individual seja a única explicação do mundo" (BORDINI, 2010, p. 150). A solidão estaria muito relacionada, assim, com "os anseios de dominação totalitária" (BORDINI, 2010, p. 150).

\section{Um homem verdadeiramente sozinho e individual}

Além do alheamento, Walser também era caracterizado pela imobilidade e pelo mutismo, o que ficava bem evidente em sua relação com Klober, o encarregado. Os diálogos entre ambos quase não pressupunham a voz de Walser: este praticamente só ouvia, enquanto Klober só falava (quase "discursava”). Essa característica de Joseph Walser se sobressai, também, na própria construção do texto. Só temos acesso aos pensamentos do personagem através do narrador, quando este "cola-se" à sua perspectiva, procedimento muito utilizado, aliás, pelo narrador deste e de outros romances de $O$ Reino. Quase não há o discurso direto: apenas quando se trata de representar a fala de Klober.

A imobilidade é objeto de reflexão de Gonçalo M. Tavares, em Atlas do Corpo e da Imaginação:

A imobilidade é a manifestação pública de um segredo corporal, é um não querer falar, é um não querer tomar partido. De certa maneira, a imobilidade é uma posição não política, que não intervém na cidade; que não avança, precisamente, nem para um lado, nem para o outro (TAVARES, 2013, p. 211).

Qualquer movimento, ressalta Gonçalo M. Tavares, por menor que seja, constitui um "ato político", um "ato na cidade" (TAVARES, 2013, p. 211): "O movimento é sempre 
movimento político e a imobilidade indiferença ou neutralidade políticas" (TAVARES, 2013, p. 211).

Em nota, ao pé da página em que expusera sua reflexão, o autor de Atlas do Corpo e da Imaginação evoca alguns autores de diferentes áreas do conhecimento que abordaram a imobilidade. Dentre eles, cita Sartre que, em A Náusea, explora o tema no seguinte trecho: "Tenho na mão direita o cachimbo e na esquerda a bolsa do tabaco. Era preciso encher o cachimbo. Mas falta-me coragem” (SARTRE, s/d, p. 44 apud TAVARES, 2013, p. 211). Tal abordagem traduz uma certa imobilidade que, segundo Tavares, "[...] aproxima-se da inércia, da imobilidade que já desistiu" (TAVARES, 2013, p. 211). Outro autor citado é Thomas Bernhard, que também explorou em suas reflexões esta imobilidade que "já desistiu": "Destapámo-nos de noite/ e quase morremos de frio/ e não temos pachorra/ para puxar o cobertor para cima" (BERNHARD, 1991, p. 159 apud TAVARES, 2013, p. 211). Trata-se de uma inércia, afirma Gonçalo M. Tavares, que está associada a uma necessidade de solidão: "queremos ficar sossegados/ e batem-nos à porta" (BERNHARD, 1991, p. 176 apud TAVARES, 2013, p. 211).

Nietzsche, "pensador que caminha", segundo Tavares, escreve, em Ecce Homo:

Estar o menos possível sentado; não confiar em ideia alguma que não tenha surgido ao ar livre enquanto caminhamos, em nenhuma ideia na qual os músculos não tenham festiva parte. Os preconceitos nascem dos intestinos. A sedentaridade - já uma vez o disse - é o autêntico pecado contra o Espírito Santo (NIETZSCHE, 1984, p. 49 apud TAVARES, 2013, p. 211).

Ou seja, há, no caso de Nietzsche, uma espécie de elogio do movimento e crítica à imobilidade, que se mostra, neste caso, perigosa. Esta abordagem aproxima-se bastante àquela explorada em A Máquina de Joseph Walser, muito evidente na caracterização do protagonista.

$\mathrm{O}$ desapego indumentário de Walser, aliado a outras características do personagem sobre as quais já falamos, direciona-se ao desprezo que ele sentia pelo mundo externo. Interessava-lhe o mundo interior. Podemos dizer que, interiormente, Walser vivia um alto grau de agitação e movimento, enquanto que, exteriormente, sua conduta era pautada na imobilidade e na indiferença.

Quanto ao título do romance, é interessante tecer alguns comentários. Em quase todos os romances da tetralogia, o título traz o nome do protagonista. Temos, como exceção, apenas Jerusalém. No entanto, o título A Máquina de Joseph Walser, da forma como fora construído, dá a entender que há um elemento - a máquina - que pertence a um ser - Joseph Walser. $\mathrm{O}$ 
fato de algo pertencer a uma pessoa traz a ideia de domínio ou controle sobre esse algo. Sendo assim, de acordo com o título, Walser é possuidor dessa máquina que, a princípio, não sabemos exatamente o que é. Tal leitura do título mostra-se quase como uma provocação, se levarmos em conta o contexto do livro, já que veremos que é a máquina quem "controla" Walser dita as regras a partir das quais a existência do personagem irá se configurar; possui quase um status de divindade, na medida em que é ela quem o pode salvar ou matar.

É interessante observar essa questão, já que, ao fazermos a leitura completa do romance, essas possíveis expectativas, que poderiam ter sido criadas a partir do título, são quebradas. Walser mostra-se dependente da máquina, a ponto de confundir-se com ela e só se sentir "pleno" quando a manipula ou a toca, o que emblematiza a crítica à técnica embutida no romance.

Levando em conta pressupostos arendtianos, podemos observar em Joseph Walser traços que demarcam a personalidade de um indivíduo banal, na medida em que age sem levar em conta as necessidades dos outros, pois não tem a capacidade de pensar sob outro ponto de vista que não o próprio. Walser não faz nada para evitar que o seu "amigo" Fluzst seja fuzilado; inicia, após a morte deste, uma inescrupulosa relação com a viúva de Fluzst: Claire; não esboça a mínima reação diante do adultério cometido pela esposa, Margha, como também não reage diante da infelicidade desta. Joseph Walser incorpora, assim, a banalidade do $\mathrm{mal}^{2}$, na medida em que demonstra a sua total incapacidade de pensar do ponto de vista de outra pessoa.

Bordini alude a uma escritora francesa, Claudine Haroche, que, por ocasião do cinquentenário do livro de Hannah Arendt Eichmann em Jerusalém, escreveu um ensaio, no qual caracteriza o que ela denomina de "personalidade totalitária" que, segundo Arendt, consistiria em um "perfil individual que foi moldado e privilegiado pelo contexto nazista" (BORDINI, 2010, p. 31). Segue o trecho em que a autora francesa expõe o que seria esse perfil, na perspectiva de Arendt:

Arendt insistirá muito sobre o fato de que no totalitarismo o fator inquietante era o "autêntico desinteresse de seus partidários" pelo mundo, pelos outros. A principal característica do homem de massa "não é a brutalidade ou o retardo mental, mas o isolamento e a falta de relações sociais normais' que o levam então à organização. Arendt observa que é a 'identificação com o movimento e o conformismo absoluto (que) parecem

2 Conceito desenvolvido por Hannah Arendt em Eichmann em Jerusalém: um relato sobre a banalidade do mal. Nesta obra a autora relata o julgamento do oficial nazista Adolf Eichmann, ressaltando a sua personalidade banal, na sua incapacidade de pensar do ponto de vista de outra pessoa. 
ter destruído até sua capacidade de viver uma experiência mesmo no caso da tortura ou do medo da morte' (HAROCHE, 2013, p. 103-104 apud BORDINI, 2010, p. 31) 3i $^{\mathrm{i}}$

Por isso, para Bordini, a omissão de Walser é considerada uma "omissão agressiva": “[...] pois se trata da omissão de alguém que não apenas deseja se abster da vida em comum com outros homens, mas que não se incomoda em deixar morrer esses outros homens. É uma espécie de omissão com espírito totalitário" (BORDINI, 2010, p. 65).

É aí que residirá a "força" de Walser: "qualquer aproximação a outra existência, não sendo ainda para a eliminar, era já, e desde há muito, para não amar” (TAVARES, 2010, p. 129). Ao compararmos o protagonista deste romance com os dos outros três, que possuem um comportamento muito mais voltado ao movimento, como é o caso de Lenz Buchmann e Klaus Klump $^{4}$, em especial, podemos chegar à conclusão precipitada de que Walser constitui um personagem "fraco", seguindo a lógica de forças predominante dos quatro romances. No entanto, ao fazemos uma análise mais profunda e com base na própria leitura do romance, chegaremos à conclusão oposta: embora a conduta de Walser seja pautada na passividade, este é, sem dúvida, um personagem "forte". Sua "força" residirá, justamente, nesse não envolvimento, nesse afastamento total em relação ao outro: sua "arma de guerra", que o protegeria da fragilidade humana.

É o próprio personagem quem chega a essa conclusão, após ouvir um dos longos discursos proferidos por Klober, em que o encarregado discorre sobre o que seria um "grande homem":

E Walser não pôde deixar naquele momento de ser capturado por um orgulho: ele, sim, era um grande Homem, um Homem, como defendia Klober, que conseguia estar separado de todos os outros, um homem verdadeiramente sozinho e individual. Porque precisamente os seus actos pareciam não ter qualquer ligação às outras pessoas, como se estas não existissem. Estavam separados: ele e os outros; os seus actos eram independentes, autônomos, e esta era a sua grandeza (TAVARES, 2010, p. 129).

Segundo Bordini, a "arma de guerra" de Walser, a "arma da indiferença radical" (BORDINI, 2010, p. 30) não será suficiente, entretanto, para enfrentar o encarregado Klober. Walser acaba ficando encurralado no jogo letal proposto por Klober e é obrigado a se

3 Referência completa do trecho citado: HAROCHE, Claudine. Crueldade da personalidade totalitária, crueldade da personalidade ilimitada, pp. 103-104. In: BREPOHL, Marion (org). Eichmann em Jerusalém: 50 anos depois. Curitiba: Editora UFPR, 2013.

4 Protagonistas de Aprender a rezar na era da técnica e de Um homem: Klaus Klump, respectivamente. 
posicionar. O jogo que ocorre ao final do romance, a roleta russa combinada ao jogo de dados, acaba por aprisionar Walser na teia de Klober e o seu escudo de indiferença que, supostamente, o protegia de tudo e de todos, cai por terra.

\section{Walser e a "sua" máquina}

A relação homem-máquina é o eixo temático a partir do qual se desenvolve o enredo de A Máquina de Joseph Walser. Extremamente complexo, este tema é problematizado por Gonçalo M. Tavares de uma forma muito peculiar e exige do leitor uma análise vagarosa e atenta. Vários são os teóricos que se debruçaram sobre o assunto e é difícil elencar aqueles que podem dialogar de maneira apropriada com nossas reflexões. Porém, percebemos que o texto de Hannah Arendt - em especial a obra A condição humana - traz considerações teóricas que se aproximam de nossa leitura desta principal questão desenvolvida no romance.

Hannah Arendt trabalha com o conceito de vita activa. Esta dividir-se-ia em três categorias fundamentais: o labor, o trabalho e a ação. A autora as chama de fundamentais porque "a cada uma delas corresponde uma das condições básicas mediante as quais a vida foi dada ao homem na Terra" (ARENDT, 2007, p. 15). A filósofa define o labor como sendo "a atividade que corresponde ao processo biológico do corpo humano, cujo crescimento espontâneo, metabolismo e eventual declínio têm a ver com as necessidades vitais produzidas e introduzidas pelo labor no processo da vida" (ARENDT, 2007, p. 15). A condição humana do labor é, desta forma, a própria vida.

O trabalho estaria relacionado com a fabricação de bens e coisas duráveis: através dele, o homo faber constrói um mundo artificial de coisas: "O trabalho é a atividade correspondente ao artificialismo da existência humana, existência esta não necessariamente contida no eterno ciclo vital da espécie, e cuja mortalidade não é compensada por este último" (ARENDT, 2007, p. 15). A condição humana do trabalho seria a "mundanidade". O mundo de coisas produzido pelo homo faber é chamado de artificial pelo fato de se mostrar bem diferente de qualquer ambiente natural.

A ação "corresponde à condição humana da pluralidade, ao fato de que os homens, e não o Homem, vivem na terra e habitam o mundo" (ARENDT, 2007, p. 15). Hannah Arendt afirma que apenas a ação constitui uma atividade que é exercida diretamente entre os homens, "sem a mediação das coisas ou da matéria" (ARENDT, 2007, p. 15). Luciano Oliveira, autor 
de 10 lições sobre Hannah Arendt, apresenta-nos esses conceitos de forma clara e objetiva, destacando o seguinte:

[...] se o animal laborans é regido pela 'necessidade', e se o homo faber age de acordo com os critérios de 'utilidade' e 'instrumentalidade', o homem arendtiano 5 está destinado a um destino mais nobre: 'às 'ociosas' ações e opiniões que constituem a esfera dos negócios humanos' $(\mathrm{CH}, 242)$ ”. (OLIVEIRA, 2014, p. 59).

Arendt salienta o fato de, na modernidade, o animal laborans (como ela chama o homem que labora) ter tido uma espécie de "vitória" sobre o homo faber. Assim, "na sociedade contemporânea, uma 'sociedade de operários', o trabalho passa a ser realizado como labor (o processo biológico do ser humano) e os instrumentos assumem 'caráter ou função mais que meramente instrumental"” (BORDINI, 2014, p. 143). Oliveira nos lembra que todos somos animal laborans, na medida em que todos nós, seres dotados de um corpo, precisamos ser providos diariamente. Trata-se de uma condição da qual não se pode fugir. No entanto, para Arendt, o perigo reside no fato de, com a supremacia do labor, outras atividades inerentes à condição humana terem sido sacrificadas, "em benefício da abundância, que é o ideal do animal laborans (CH, 138)" (OLIVEIRA, 2014, p. 61).

Oliveira destaca, ainda, que "O labor, estando regido pela lógica de uma necessidade inesgotável, ao invadir e finalmente dominar as outras atividades da vita activa submete o trabalho à sua lógica" (OLIVEIRA, 2014, p. 63). O perigo é ainda pior quando entendemos que, "no caso da ação, que deveria ser regida pelo princípio da liberdade, Arendt aponta para o perigo de morte que ronda sua própria existência" (OLIVEIRA, 2014, p. 63), o que fica muito claro na seguinte passagem:

Ao invés da ação, a sociedade [moderna] espera de cada um dos seus membros um certo tipo de comportamento, impondo inúmeras e variadas regras, todas elas tendentes a 'normalizar' os seus membros, a fazê-los 'comportarem-se', a abolir a ação espontânea ou a reação inusitada." (ARENDT, 2007, p. 50).

Na predominância do labor sobre o trabalho, os instrumentos passam a ter um caráter não mais meramente instrumental. Com a inserção das máquinas, após a Revolução Industrial, isso fica muito mais evidente. Homem e máquina passam por um processo de indiscernibilidade e é o homem que se adequa às condições impostas pela máquina e não o inverso:

5 Observe-se que, embora Hannah Arendt não se refira a isso diretamente, quando ela utiliza o termo "homem" está se referindo ao homem ligado à categoria da vita activa da ação. 
Neste movimento, os instrumentos perdem seu caráter instrumental, e desaparece a clara distinção entre o homem e os seus utensílios. O que preside o processo de labor e todos os processos de trabalho executados à maneira do labor não é o esforço intencional do homem nem o produto que ele possa desejar, mas o próprio movimento do processo e o ritmo que este impõe aos operários. Os utensílios do labor aderem a este ritmo até que o corpo e o instrumento passam a agitar-se no mesmo movimento repetitivo, isto é, até que, no uso das máquinas-que, entre todos os utensílios, melhor se adaptam à 'performance' do animal laborans-já não é o movimento do corpo que determina o movimento do utensílio, mas sim o movimento da máquina que impõe os movimentos ao corpo (ARENDT, 2007, p. 159).

Em A Máquina de Joseph Walser, essa fusão homem-máquina está muito presente e é representada pela relação do protagonista com a máquina com a qual trabalha (ou para a qual trabalha?). Walser é um animal laborans. Os movimentos do seu corpo vão, pouco a pouco, se adequando aos movimentos que a máquina lhe impõe, não podendo, inclusive, haver "erros". A máquina exigia de Walser uma "atenção exacta", uma espécie de abandono de sua humanidade, já que a total exatidão não é possível para o ser humano, assim como não o é a perfeição.

Há um momento da narrativa que é emblemático: o narrador descreve, em determinado ponto, a sintonia entre o som do motor da máquina em funcionamento e o batimento cardíaco de Joseph Walser: "Em diversos momentos o som do motor e o seu trepidar confundem-se com o bater cardíaco, pois ambos os "órgãos" estão em pleno funcionamento, em plena excitação, e encostados um ao outro misturam-se [...]" (TAVARES, 2010, p. 53). Mas a profundidade desta ligação só é sentida por Walser quando, em determinados momentos da rotina de trabalho, o motor cessa, pois o personagem sente como se o próprio coração tivesse parado de bater. Segue o excerto:

O cessar repentino provoca na sua pele um frio instantâneo, uma sensação rápida e tão desagradável que o faz, por exemplo, procurar em livros científicos a descrição pormenorizada do que sente alguém quando o coração falha. Walser tenta perceber se a separação brutal entre o funcionamento do seu coração e o funcionamento do motor da máquina não é algo semelhante à separação entre um coração de um homem e esse mesmo homem. Tinha lido que um ataque cardíaco não mortífero era relatado assim: o órgão afasta-se de nós, a grande velocidade...mas depois regressa.

O coração afasta-se do resto do corpo. Afasta-se, esta palavra era a fundamental. Havia uma distância percorrida nos acidentes cardíacos, uma distância percorrida internamente: um dos órgãos essenciais afastava-se, caminhava no sentido oposto ao resto do corpo. E era isso que Walser sentia quando estava excitado e engolido pelo funcionamento da sua máquina e esta parava de repente; e parava não por uma razão obscura, não por algo que merecesse raciocínio para ser compreendido, parava simplesmente 
porque eram doze horas, e às doze horas o motor de cada máquina era desligado na central da fábrica (TAVARES, 2010, p. 53).

A perturbação causada por essa sensação de quase morte experimentada pelo personagem, a cada vez que não ouvia o motor da máquina em funcionamento, era tamanha que ele chega a inventar uma espécie de experiência para tentar compreender o que seria o órgão separar-se do corpo, temporariamente, conforme lera sobre a descrição do infarto não fatal, em livro especializado:

Nesta interrupção por vezes Walser fazia algo que, se fosse observado do início ao fim, poderia levar a catalogarem-no de louco: aproximava-se de uma das mesas de trabalho, encostadas a uma parede, e puxava-a, como que a querer sentir a força que separar exige e, ao mesmo tempo, o fácil que é fazer esse acto. A mesa era de madeira maciça, uma mesa pesada, compacta, carregada de instrumentos; e Walser, em vez de aproveitar o tempo de paragem do motor da máquina para descansar, sem qualquer planejamento prévio, instintivamente, aproximava-se da mesa e afastava-a, então, com esforço, da parede. Diversas vezes havia sido recriminado devido a este gesto ineficaz e ligeiramente perturbador, mas não era o afastamento de alguns centímetros de uma mesa que iria provocar a queda da fábrica, isso era evidente. $O$ facto era que aquele gesto era perfeitamente desnecessário (TAVARES, 2010, p. 54).

Vejamos agora esta relação homem-máquina, problematizada no romance referido, neste capítulo, sob outro viés. Lembremos que a vida de Joseph Walser mostra-se esvaziada de sentido. A ausência de relações interpessoais significativas pode ser um dos catalisadores para que ocorra o processo de nulificação experimentado pelo personagem. Em uma espécie de busca existencial pela reconstrução de sentido em sua vida, Walser estabelece com a máquina com a qual trabalha uma relação quase afetuosa. A relação simbiótica que o personagem desenvolve com a máquina possibilita-nos, também, a abertura para uma discussão acerca de como a "racionalidade moderna propôs-se [...] a conotar a vida humana de significado, isto é, determinou-se a ocupar o lugar transcendente e divino liberado pela religião enquanto expoente máximo da cultura ocidental” (SOUSA, 2007, p. 99). Segundo Sousa:

Esta hegemonia racional traduziu-se durante o século XIX num crescente optimismo antropológico que pereceu perante a falta de um discurso autocrítico. A vertente racional que mais incide no romance tavariano é aquela da galopante evolução da civilização suportada pela já referida emancipação técnica que se vai revelar $\mathrm{em} \mathrm{JW}^{6}$ como castradora do progresso, da liberdade e da verdade que proclamava, sendo a prova maior desse facto as duas guerras mundiais que acarretam uma dimensão catastrófica, bárbara e irracional da Humanidade. A técnica e o uso indevido

6 "JW" é a sigla utilizada pelo autor para abreviar o nome do romance A Máquina de Joseph Walser. 
da técnica vão remeter o ser humano para uma existência insegura e inquieta na qual o indivíduo é confrontado com a possibilidade da sua aniquilação através da nadificação da sua própria identidade, seja por acção própria e interferência da técnica como sugere o romance JW. É inerente à ideia de supressão ou aniquilação da identidade do sujeito pela técnica uma dimensão niilista do existir que advém do progresso racional, da relação do homem com a máquina (SOUSA, 2007, p. 99).

A técnica entra no lugar do divino. A máquina representa essa constatação, de maneira simbólica, no romance. Para Walser, ela era-lhe algo superior: ao mesmo tempo amado e temido: "Eram para ele claras as hierarquias das duas existências: a máquina era de uma hierarquia superior: poderia salvá-lo ou destruí-lo" (TAVARES, 2010, p. 21). Diante de seu único deslize, seu único "pecado", o personagem sofre consequências, como se tivesse sido “punido" pela máquina com a amputação de uma parte do seu corpo. Sente-se, inclusive, culpado, como se a tivesse "traído": "Em primeiro lugar, havia uma sensação de culpa. Era ele que a tinha abandonado; ou dito de outra forma: ele falhara, já não se encontrava em condições para corresponder às exigências. Ao perder um dedo traíra a máquina". (TAVARES, 2010, p. 85). Joseph Walser "pecara” e, por isso, é "expulso" de seu "paraíso", de um mundo do qual adorava fazer parte: "Havia nele a sensação de que fora expulso de um mundo, do mundo das máquinas, e que já não era tolerada a sua presença. Tendo perdido um dedo perdera também as condições que impunham respeito a esse universo" (TAVARES, 2010, p. 86).

Segundo Sousa, Gonçalo M. Tavares trabalha o tema da relação homem-máquina de maneira inusual, na medida em que não há

[...] relação de exterminação do homem por qualquer mecanismo, mas uma vontade consciente de Joseph Walser em fundir-se com o seu instrumento de trabalho com o intuito de realcançar um eixo de significação existencial que não lhe é acessível por via social (SOUSA, 2007, p. 14).

A carência e o relacionamento falido com Margha são as causas, segundo Sousa, da alienação vivida pelo protagonista. A impossibilidade da concretização desse tipo de relação homem-máquina acaba sendo constatada e ocorre a aniquilação do corpo, elemento central do romance, tido como "objecto informe".

Tal aniquilação fica evidente no episódio da amputação do dedo que Walser sofre. Devido a um único instante de desatenção, sua mão escorrega para um sítio perigoso, causando a perda irreparável de uma parte do corpo do protagonista. Entretanto, mesmo após o acidente, Walser ainda nutria o mesmo "afeto" pela "sua" máquina. Em determinado 
momento da narrativa, ao aproximar-se dela, toca-lhe, sentindo o calor que dela emana e, neste momento, sente-se pleno, como se a falta do dedo não mais existisse:

Como alguém que pertencesse já a uma diferente espécie animal, Walser fez nesse dia o que nunca mais se atreveu a repetir: quando a máquina estava já em repouso, com o motor desligado, aproximou-se, com essa mão tocou na máquina, ao de leve, de lado, no metal, sentindo nesse toque, estranhamente, como que uma reconstituição do dedo que lhe havia sido amputado; e sorriu.

—Ainda está quente, disse (TAVARES, 2010, p. 86).

É interessante destacar que o significado da amputação vai além do físico: Walser acaba por sofrer uma espécie de impedimento de suas vontades. O personagem se dá conta deste fato quando, no costumeiro jogo de dados com os colegas de trabalho, percebe a diferença dos movimentos ao pegar nos dados:

Nos primeiros momentos, em que provocado principalmente por Stumm, Joseph se obrigara a rodar os dados na sua mão direita, a sensação fora profundamente desagradável. Os gestos que havia feito vezes sem conta com os cinco dedos, em pequenos movimentos que faziam rodar os dados, estavam agora limitados, e Joseph sentia-no exacto instante em que os dados chegavam ao sítio onde antes existia o dedo indicador e se viam obrigados a não avançar nessa direção, mas sim a recuar precisamente para a palma da mão, descendo do polegar para o dedo mais longo e deste avançando outra vez para o dedo mínimo-, e neste momento, então, Walser sentia que alguém, ou algo, lhe havia roubado não apenas uma parte do corpo, mas movimentos. E esta consciência mudava completamente o entendimento que Walser fazia do acidente: mais do que uma parte material e objectiva-como era o dedo e como ele sempre havia entendido as partes do seu corpo-haviam-lhe roubado possibilidades de movimento; numa palavra: vontades. Existiam intenções que agora não podia desenvolver (TAVARES, 2010, p. 92).

Em Atlas do Corpo e da Imaginação, Gonçalo M. Tavares aborda a questão do desejo. Segundo o autor, esta capacidade seria a causa da supremacia humana: "O homem não é o grande animal dos desejos por ter o cérebro grande e o polegar oponível, o homem tem o cérebro grande e o polegar oponível porque é o grande animal dos desejos" (TAVARES, 2013, p. 160). E os animais? Eles não desejam? Segundo Gonçalo M. Tavares, os animais desejam, mas não como o Homem: "Aqueles, os do animal, são desejos de fraca potência, desejos animalescos, precisamente, e não humanos" (TAVARES, 2013, p. 160). Seguindo esta linha de pensamento, fica mais evidente perceber a diferença: o Homem tem, assim como os animais, desejos "de fraca potência", como, por exemplo, fome; mas tem muito mais: "Ouvir mais longe, ver mais longe, eis dois exemplos de desejos simples, mas que deram 
origem a coisas materiais, a invenções de instrumentos, a indústrias, a elementos concretos que tornam a civilização humana mais forte" (TAVARES, 2013, p. 160).

Para o autor, o desejo humano está à frente, até mesmo, da inteligência: “[...] é nos desejos que o Homem começou a distinguir-se; sem estes, o cérebro enorme estaria parado, sem nada para fazer. O Homem quer fazer porque tem desejo, consegue fazer porque tem cérebro" (TAVARES, 2013, p. 160). É justamente neste pormenor - no desejo - que Walser é atingido. Logo, sendo limitado em sua capacidade de desejar, o personagem acaba por tornarse, poderíamos dizer, "menos humano":

[...] em poucas semanas estava consumada a amputação mais violenta: a de um desejo. A sua imaterialidade havia sofrido um acidente, como que defasado no tempo do acidente concreto e real. Não havia aqui uma data exacta como existira para o seu acidente com a máquina, mas três meses depois dessa primeira data objectiva, assinalável no calendário, Walser tinha já perdido algo mais (TAVARES, 2010, p. 93).

\section{Considerações finais}

A máquina de Joseph Walser é um romance que nos faz pensar. É muito provável que o leitor, ao chegar ao final da empreitada, sinta-se, no mínimo, perturbado. Não só em se tratando do tema, mas igualmente do trabalho com a linguagem, este texto ficcional promove o choque. E não poderia ser de outra forma. Afinal, como escrever uma obra que aborda aspectos sombrios do Homem, sem fazer uso de uma linguagem cortante? Esta parece ser uma das metas de Gonçalo M. Tavares, ao produzir não só este romance, mas a tetralogia "O Reino" como um todo: promover a lucidez no leitor. Em mais de uma entrevista, Gonçalo aborda esta questão, deixando clara a sua intenção como autor: fazer pensar, perturbar, provocar a reflexão.

Em entrevista à Entrelivros, o autor afirma que:

Se neste século a literatura não nos fizer pensar, o que é que nos vai fazer pensar? A televisão, o teatro, o cinema, as artes? Bem, eu acho que tudo isto pode ajudar-nos a pensar, mas, apesar de tudo, penso que a literatura ainda é, e deve ser cada vez mais o espaço por excelência do pensamento, da reflexão, enfim, da lucidez. E não precisa de ser pensamento filosófico, nada disso. Através de uma história podemos fazer pensar. Mas claro que não é uma historieta qualquer, não pode ser novela porque aí a televisão faz melhor. A literatura é outro mundo, é o mundo em que alguém está a ler um livro e pára, se necessário, numa linha, numa frase e interrompe a leitura e a partir dessa frase, se necessário, reflete ou põe em causa toda a sua vida (TAVARES, 2007, p. 4). 
Desta forma, encerramos este artigo com esta proposta de reflexão. E mais: chegamos ao término deste pequeno estudo com, também, um desejo: que nós, leitores, estudiosos da literatura, acadêmicos, professores, possamos repensar a nossa própria humanidade, assim como o caminho que estamos percorrendo hoje. Que possamos, após nos defrontarmos com um personagem intrigante como Joseph Walser, vislumbrar o lado sombrio e perverso do Homem: seu individualismo, sua relação confusa com a técnica e com os outros homens. Que a literatura possa nos proporcionar, senão uma mudança imediata, ao menos uma mudança de perspectiva, de direção do pensamento. Nesse sentido, findamos nosso escrito com a ideia de que A máquina de Joseph Walser é, em nossa visão, muito mais do que um simples livro: é um convite à reflexão.

\section{Referências}

ARENDT, Hannah. Eichmann em Jerusalém. Um relato sobre a banalidade do mal. São Paulo: Companhia das Letras, 2000.

A condição humana. Trad. Roberto Raposo. 10 ed. Rio de Janeiro: Forense Universitária, 2007. Disponível em: https://www.google.com.br/url?sa=t\&rct=j\&q=\&esrc=s\&source=web\&cd=1\&cad=rja\&uact= 8\&ved=0CB8QFjAAahUKEwiU5JaupffIAhUDE5AKHbh7Ad4\&url=http\%3A\%2F\%2Fww w.libertarianismo.org\%2Flivros\%2Fhaach.pdf\&usg=AFQjCNGFvjHfngBFHW0xyNPbS0s1 bljTQ\&sig2=nNSrK_zzWEfQjw3NokpOvw. Acesso em 15 mar. 2016.

. Origens do totalitarismo. São Paulo: Companhia das Letras, 1989.

BORDINI, Maria Isabel da Silveira. O poder e a violência em O Reino, de Gonçalo M. Tavares. Dissertação de Mestrado. Curitiba: UFPR, 2014. 187 f. Disponível em: http://dspace.c3sl.ufpr.br/dspace/bitstream/handle/1884/37170/R\%20-\%20D\%20\%20MARIA\%20ISABEL\%20DA\%20SILVEIRA\%20BORDINI.pdf?sequence=3\&isAllowe d=y. Acesso em: 15 mar. 2016.

OLIVEIRA, Luciano. 10 lições sobre Hannah Arendt. 4 ed. Petrópolis, RJ: Vozes, 2014.

SOUSA, Pedro Quintino de. Literatura e Filosofia: Uma Leitura dos Romances de Gonçalo M. Tavares. Dissertação de Mestrado apresentada à Faculdade de Ciências Humanas e Sociais da Universidade de Algarve, como requisito para a obtenção do título de Mestre em Literatura-Especialização em Literatura Comparada. Orientador: Prof. Dr. Petar Petrov. Faro: UALG, 2007. Disponível em: http://sapientia.ualg.pt/bitstream/10400.1/262/1/Literatura\%20e\%20Filosofia\%20\%20uma\%20leitura\%20dos\%20romances\%20de\%20Gon\%C3\%A7alo\%20M.\%20Tavares.pd f. Acesso em 15 mar. 2016. 
TAVARES, Gonçalo M. A máquina de Joseph Walser. São Paulo: Companhia das Letras, 2010.

Atlas do corpo e da imaginação. Teoria, fragmentos e imagens. Alfragide: Editorial Caminho, 2013.

\begin{tabular}{lccc}
. "Ler para ter lucidez". Entrevista concedida a Joca & Terron para o site Entrelivros, \\
\hline setembro & 2007. & Disponível & em:
\end{tabular} http://www2.uol.com.br/entrelivros/artigos/goncalo_m_tavares_-ler_para_ter_lucidez-.html. Acesso em: 15 mar. 2016.

\title{
The removal of the human: isolation, immobility and the man-machine interface. $A$ reading of the $A$ Máquina de Joseph Walser
}

\begin{abstract}
In A Máquina de Joseph Walser, Gonçalo M. Tavares's novel, we observe the construction of a character who symbolizes man's departure from his own humanity. Joseph Walser, protagonist of this novel that is part of the second stage of a tetralogy called by the author as "O Reino", has characteristics such as isolation, immobility and alienation. According to Hannah Arendt such characteristics would be on those that led to the totalitarian spirit. The man-machine interface is also of fundamental importance in this "tavarian" fictional text, making clear the transformation of work into labor, making the machine/tool take a dimension that transcends the merely instrumental; it becomes part of the life cycle. The man starts to abide to the conditions imposed by the machine and not the other way, which contributes again to the dehumanization of the man, who now appears as laborans animal. In our analysis we often use the theoretical reflections of Hannah Arendt in Origens do Totalitarismo; A Condição Humana e Eichmann em Jerusalém: um relato sobre a banalidade do mal. In addition, we also alluded to some reflections of Gonçalo M. Tavares himself, in Atlas do Corpo e da Imaginação: teoria, fragmentos e imagens, works of the contemporary Portuguese cited author who articulates literary criticism with philosophical reflection.
\end{abstract}

Key words: Dehumanization. Portuguese contemporary literature. Man-machine interface.

Recebido em: 15 de março de 2016.

Aprovado em: 13 de julho de 2016. 